Published in final edited form as:

Oncologist. 2009 February ; 14(2): 125-136. doi:10.1634/theoncologist.2008-0200.

\title{
Management of Mucin-Producing Cystic Neoplasms of the Pancreas
}

\author{
Stefan Fritz, Andrew L. Warshaw, and Sarah P. Thayer \\ Department of Surgery, Massachusetts General Hospital, Boston, Massachusetts, USA
}

\begin{abstract}
During the last decade small lesions of the pancreas have been increasingly recognized in clinical practice. Among these lesions, mucin-producing cystic neoplasms represent a recently described and unique entity among pancreatic tumors. In 1996, the World Health Organization distinguished two different types of mucinous cystic tumors: intraductal papillary mucinous neoplasms (IPMNs) of the pancreas, which are characterized by mucin production, cystic dilation of the pancreatic ducts, and intrapapillary growth, and mucinous cystic neoplasms (MCNs), which are defined by ovarian-like stroma and in most cases do not communicate with pancreatic ducts. Further, IPMNs can be subdivided into main-duct type, mixed-type, and branch-duct type tumors. Older data did not distinguish among different subsets of cystic neoplasms of the pancreas, and consequently many databases were inconsistent. Histopathologically, both IPMNs and MCNs demonstrate a wide spectrum of cellular atypia ranging from mild mucinous hyperplasia to invasive adenocarcinoma. Because mucinous cystic neoplasms of the pancreas show significant differences in clinical behavior from patient to patient, knowledge of the clinicopathologic characteristics and natural history of specific subtypes of IPMNs and MCNs has become crucial for physicians working in the field of gastroenterology. The present work offers an overview of current and generally accepted clinical guidelines for the diagnosis and treatment of IPMNs and MCNs.
\end{abstract}

\section{Keywords}

Pancreas; Intraductal papillary mucinous neoplasm; Mucinous cystic neoplasm; Pancreatectomy; IPMN; MCN

\section{Introduction}

Mucin-producing cystic neoplasms of the pancreas have become a well-recognized entity [1, $2]$. Today, in experienced centers, they are diagnosed in approximately $10 \%-20 \%$ of resected pancreatectomy specimens [3-7]. In the Japanese literature, Ohhashi et al. [8] described, for the first time, four cases of mucinous neoplasms of the pancreas. They initially called these lesions "mucin-producing cancer" that affected the main pancreatic duct and produced excessive quantities of mucus. In contrast to only a few descriptions before 1990, an autopsy study in 1995 found small mucinous cystic lesions in $24.3 \%$ of

\section{CAlphaMed Press}

Correspondence: Sarah P. Thayer, M.D., Ph.D., Department of Surgery, Massachusetts General Hospital, 15 Parkman Street, WACC 460, Boston, Massachusetts 02114, USA. Telephone: 617-726-0624; Fax: 617-726-0630; sthayer@ partners.org.

Disclosures: Stefan Fritz: None; Andrew L. Warshaw: None; Sarah P. Thayer: None

Author Contributions

Conception/design: Stefan Fritz

Manuscript writing: Stefan Fritz; Andrew L. Warshaw; Sarah P. Thayer

Final approval of manuscript: Stefan Fritz; Andrew L. Warshaw; Sarah P. Thayer 
pancreata. Histologically, most of the lesions displayed intraductal papillary mucinous neoplasms (IPMNs) with low-grade dysplasia (benign adenomas). Atypical hyperplasia was diagnosed in $16.4 \%$, and carcinoma in situ was diagnosed in $3.4 \%$ of the cases [9]. In the past two decades, with the use of high-resolution abdominal imaging techniques, similar cystic pancreatic lesions are increasingly identified incidentally [4], and a large number of patients have undergone surgical resection [10]. These cases have been described by various names, each emphasizing a different aspect of the tumor; for example, villous adenoma [11], papillary neoplasia [12], papillary carcinoma, mucinous pancreatic duct ectasia [13], or mucin-producing tumors of the pancreas [6]. To evaluate whether IPMN represented a new disease or had lain unrecognized among cases of other cystic neoplasms or chronic pancreatitis, Tollefson et al. [14] reviewed the histology of 84 patients resected at the Mayo Clinic between 1960 and 1980. They found that IPMNs had in fact existed prior to 1982; however, they could not determine whether the prevalence or incidence of these tumors had changed since attention was called to them.

In 1996, in order to describe and categorize this "new" entity of cystic lesions in the pancreas, the World Health Organization (WHO) separated the mucin-producing pancreatic neoplasms into intraductal papillary mucinous tumors and mucinous cystic tumors [15]. In its 2000 revision, the WHO renamed these two categories IPMNs and mucinous cystic neoplasms (MCNs) [16]. Based on the degree of cytologic and architectural dysplasia, noninvasive IPMNs have recently been subcategorized into those with low-grade dysplasia (previously called IPMN adenomas), those with moderate dysplasia (previously called borderline IPMNs), and those with high-grade dysplasia (previously called carcinoma in situ) [17]. IPMNs can be further subclassified into main-duct type (20\%), mixed-type (40\%) and branch-duct type (40\%) [18]. Main-duct IPMNs involve primarily the main pancreatic duct with or without extension to the side branches (mixed-type IPMN), whereas branchduct IPMNs exclusively affect branch ducts [19].

In the past few years, mucinous cystic neoplasms of the pancreas have been diagnosed more and more frequently. It has become crucial for physicians working in this field to have both a clear understanding of the biology of these tumors and practical guidelines for management of patients. Although there has been substantial progress in the understanding of the pathological and clinical behavior of these neoplasms, many questions still remain. In this review, we present suggested guidelines derived from what is currently known.

\section{Clinical Presentation}

Cystic lesions of the pancreas are much more common than previously appreciated and are increasingly diagnosed as a result of the more frequent use of imaging tests and advances in imaging techniques [20]. Pancreatic cystic lesions include inflammatory pseudocysts, benign serous tumors, mucinous neoplasms [21], cystic neuroendocrine tumors, and other rarer lesions. In recent years it has become clear that only approximately $40 \%$ of all cystic pancreatic lesions are composed of classic pseudocysts or retention cysts associated with chronic pancreatitis or previous trauma [22,23]. While these lesions are clinically and histopathologically benign, MCNs, IPMNs, cystic neuroendocrine tumors, and solid pseudopapillary neoplasms may be or may become malignant [24]. This means that $60 \%$ of all pancreatic cystic neoplasms have malignant potential.

\section{IPMNs}

IPMNs are the most frequent of the cystic pancreatic neoplasms. As opposed to serous cystadenomas, IPMNs are characterized by connection to the pancreatic ductal system and production of mucus (Table 1). They generally present between the sixth and seventh decades of life and are predominantly located in the head of the gland $(75 \%)[6,25]$. IPMNs 
may also arise in the body or tail of the pancreas (25\%), and in some cases they diffusely involve the entire gland $[7,26]$.

The natural history of this disease remains to be fully defined. However, a number of authors have noted an average lag of approximately 5 years from the age at presentation of IPMNs with low-grade dysplasia (formerly called IPM adenoma) to the point at which IPMNs are found to contain invasive carcinoma. Salvia et al. [25] found a significant difference of 6.4 years between patients with benign IPMNs (adenomas and borderline tumors) and patients with malignant IPMNs. In a study by Sohn et al. [3], the average age of patients with low-grade dysplastic IPMNs was 63.2 years, compared with 68.2 years for those with invasive carcinoma. Thus, current thinking is that IPMNs with invasive carcinoma are the product of progression and malignant transformation from pre-existing low-grade dysplastic lesions [25]. However, it is not known whether all IPMNs have that potential for progression or when it may occur [27].

Initial reports suggested that there was a male predominance for IPMNs, but more recent data suggest that the sex incidence is essentially equal $[3,25,28]$. It is notable that some IPMNs arise in association with inherited syndromes such as Peutz-Jeghers syndrome [29] or familial adenomatous polyposis [30,31], and a subset of IPMNs seem to be part of the phenotype of familial pancreatic cancer [32]. Furthermore, there is evidence that patients with IPMNs, contrasted with patients with conventional ductal adenocarcinoma, are at a higher risk of developing synchronous or metachronous primary extrapancreatic cancers. Yamaguchi et al. [33] and Eguchi et al. [34] reported that 25\% of 48 patients with IPMNs had cancers of the stomach, colon, rectum, lung, breast, or liver. Approximately $25 \%$ of IPMNs are asymptomatic at discovery and are identified serendipitously $[4,35]$. Still, a majority of patients are symptomatic with abdominal pain (41\%-60\%), weight loss (15\%$43 \%)$, diarrhea (22\%), or acholic stool (10\%) [5, 6, 19, 26, 35]. Jaundice is seen in approximately $15 \%-18 \%$ of cases and is probably an indicator of more advanced disease [5, 28 ], usually cancer. Approximately $10 \%-15 \%$ of patients have suffered an episode of acute pancreatitis at some time, presumably as a result of duct obstruction by tumor or mucous plugs $[28,36]$. The history of pancreatitis can mislead the unwary physician to attribute the dilated pancreatic duct and cystic structures to chronic pancreatitis, not neoplasms.

\section{MCNs}

MCNs present in patients who have a distinct demographic profile (Table 1), almost entirely comprising relatively young women. In a study of 130 women, the mean age at diagnosis was 44.6 years (range, 20-95 years) [37]. Most had no symptoms or only vague abdominal pain or fullness; a few had a palpable abdominal mass. Of these lesions, $93 \%-95 \%$ were found in the body and tail of the pancreas. Communication with the pancreatic duct system was very rare [37-39]. Thompson et al. [37] noted that MCNs ranged in size from 1.5-36 $\mathrm{cm}$, and most were multilocular.

As a rough rule of thumb, cystic lesions in males and those in the head of the pancreas are likely to be IPMNs, whereas cystic lesions in the body and tail in a (younger) female may be either an MCN or IPMN [40] (Table 1). In general, the presence or absence of symptoms does not favor one or the other tumor type, but the presence of jaundice is a predictor of malignancy $[5,19,28]$.

\section{Diagnostic Evaluation}

Thin-slice cross-sectional imaging studies by computed tomography (CT) [41, 42] (Fig. 1A1C) and magnetic resonance imaging (MRI or cholangiopancreatography [MRCP]) [43] (Fig. 2A) are the most useful in characterizing IPMNs [44]. These modalities provide 
accurate localization of the site of the tumor and assessment of its relationship with contiguous organs and vessels $[45,46]$. There is some evidence that MRI and MRCP may be superior to CT imaging in detecting small pancreatic duct connections or small branch-duct cysts [47].

Nodules in the main duct system and dilation of the main duct $(\geq 1 \mathrm{~cm})$ suggest main-duct IPMN (Fig. 1A). In contrast, a pancreatic mucinous cyst communicating with the pancreatic duct system outside a main duct of normal diameter indicates branch-duct IPMN [18, 4851] (Fig. 2A). Additionally, branch-duct IPMNs are typically smaller, and frequently multiple (Fig. 2B) [40]. As a complement to CT and MRI, endoscopic ultrasonography (EUS) can demonstrate fine IPMN structures, such as mural nodules or irregularities of the pancreatic duct [52]. EUS is therefore used to follow-up ambiguous findings or to better differentiate between benign and malignant IPMNs [53, 54]. Main-duct type tumors with a dilated main pancreatic duct, branch-duct type tumors $(>30 \mathrm{~mm})$ with irregular septa, or mural nodules suggest malignancy by EUS [54]. Intraductal ultrasonography and peroral pancreatoscopy [55-57] can provide sophisticated details about tumor type and extent, but these techniques are not widely available. Some groups consider cytology as part of the diagnostic evaluation of pancreatic cysts, because malignancies have been identified only by positive cytologies in what would appear to be small asymptomatic benign-appearing lesions that would not have met criteria for resection by present-day guidelines. However, the decision to proceed with non-operative management should not be based on negative cytologic features alone [58, 59]. Thus, the benefit of fine-needle aspiration (FNA) remains controversial. Preliminary data using 18-fluorodeoxyglucose positron emission tomography (18-FDG PET) suggest that PET may also prove useful in distinguishing benign from malignant cystic lesions. However, there have been no large prospective studies to validate its accuracy or superiority to standard imaging modalities such as CT or MRI [60, 61].

Cross-sectional imaging of MCNs with CT or MRI/MRCP shows a cystic lesion, usually a single cyst with or without mural nodules (Fig. 3). In contrast to pseudocysts, MCNs do not communicate with the pancreatic duct system [37], although there are rare exceptions [62]. Because patients suffering from pseudocysts usually exhibit a previous history of chronic pancreatitis associated with fibrosis, calcifications, and duct obstruction, differentiation of an MCN from a pseudocyst is usually straightforward. Cyst fluid analysis may be singularly useful in cases of uncertainty, especially in deciding between resection and drainage into the gastrointestinal tract. Analysis of cyst contents obtained by EUS-guided FNA is subjected to evaluation of viscosity, cytology, and measurement of amylase level and tumor markers, in particular carcinoembryonic antigen (CEA) [21,63]. High levels of CEA indicate a mucinous neoplastic lesion but do not reliably distinguish benign from malignant mucinous cysts. Low CEA levels are found in aspirates from pseudocysts or serous cystadenomas [64]. Cyst fluid amylase is high in pseudocysts, lower in IPMNs, and low in MCNs [21].

\section{Pathology IPMNs}

IPMNs are grossly visible, mucin-producing, predominantly papillary or (rarely) flat epithelial neoplasms arising from the main pancreatic duct or branch ducts with variable amounts of papilla formation and varying degrees of duct dilation [26, 65] (Fig. 4A). Histologically, IPMNs are composed of tall, columnar, mucin-containing epithelium with cytoarchitectural atypia, ranging from low-grade dysplasia to invasive adenocarcinoma [66] (Fig. 5A, B). Based on the grade of atypia in the epithelial cells, IPMNs can be subdivided into benign (epithelium with low-grade and moderate dysplasia) (Fig. 5A) and malignant (high-grade dysplasia and infiltrative carcinoma) [15] (Fig. 5B) neoplasms. A wide spectrum, ranging from minimal epithelial changes to sometimes frank adenocarcinoma, can 
often be seen in the same surgical specimen [6]. Components of invasive carcinoma are found in approximately $30 \%$ of main-duct IPMN patients [67-72], and generally occur adjacent to areas of high-grade dysplasia, suggesting a sequential progression of neoplastic transformation [6]. In contrast to main-duct IPMNs, the diagnosis of branch-duct IPMNs relies on the presence of one or more cystic neoplastic lesions communicating with the main pancreatic duct, but not involving it, and the absence of ovarian-like stroma [39, 40]. Many IPMNs show papillary growths in both the main duct and branch duct and have therefore been classified as mixed-type IPMNs [40]. The frequency of malignancy (high-grade dysplasia and invasive carcinoma) in main-duct IPMNs in eight series from Japan, Europe, and the U.S. has been in the range of $60 \%-92 \%$, with a mean of $70 \%[3,24,34,38,66-70]$. Compared with main-duct IPMNs, branch-duct IPMNs are less likely to contain areas of cancer [73] and rarely show infiltrating growth [74, 75]. A review of seven recent series describing branch-duct IPMNs showed a frequency of malignancy of 6\%-46\%, with a mean of $25 \%$, and a frequency of invasive cancer in the range of $0 \%-31 \%$, with a mean of $15 \%$ [3, $36,40,73-78]$. Thus, it is recommended that surgical pathologists make every attempt to determine branch versus main-duct IPMNs [79], at least to provide verification for this clinical classification [40, 79].

\section{MCNs}

MCNs usually present as thick-walled, multilocular cystic tumors in the body or tail of the pancreas that contain an ovarian-like stroma that stains for estrogen and progesterone receptors [80] (Fig. 3B). This characteristic distinguishes them from IPMNs [81] (Fig. 5C). In addition, the ovarian-type stroma of pancreatic MCNs stains for human chorionic gonadotropin in $61.8 \%$ of cases [82]. The stromal cells have typical oval nuclei and spindled cytoplasm arranged in long fascicles, which form a layer of variable thickness beneath the epithelial lining. The resemblance to ovarian stroma is further strengthened by the presence of occasional "luteinized" cells_epithelioid cells with abundant clear cytoplasm [40]. Over the past few years, it has become clear that the classification of MCN should be restricted to neoplasms exhibiting ovarian-type stroma [38, 40], a unique feature that may indicate that they arise from ovarian rests in the pancreas [39]. Similar to IPMNs, MCNs have been divided into those with low-grade, moderate grade, and high-grade dysplasia, and invasive adenocarcinoma. The prevalence of invasive carcinoma reported in MCNs has varied widely in the range of 6\%-36\% [37-39]. MCNs are generally solitary and do not recur after complete resection $[83,84]$.

It is important to note that the biological and clinical behavior of invasive adenocarcinoma arising on the background of cystic neoplasms seems to be different from the more common invasive ductal adenocarcinoma. Infiltrating carcinoma associated with IPMNs and MCNs appears to grow less aggressively and to have a lower incidence of nodal positivity and of perineural and vascular invasion [5]. Consequently, patients suffering from malignant cystic neoplasms of the pancreas are likely to have a better chance of survival after resection than patients with ductal adenocarcinoma. Whereas patients suffering from ductal pancreatic cancer have 5-year survival rates of 20\%-25\% (at best) after curative resection [85-87], patients with malignant IPMNs and MCNs have overall 5-year survival rates of 60\%-70\% $[15,25,62,64,81-85]$ and 50\%-60\%, respectively [65, 88]. Patients with benign IPMNs or MCNs with only dysplasia (including high-grade dysplasia) have a disease-specific survival rate close to $100 \%[5,28,40,66,83]$.

\section{Indication for Surgery}

In the past, a common recommendation was to remove all mucin-producing neoplasms because of the fear of ultimately developing cancer $[2,37,75,89]$. The three main goals for surgical resection are to treat symptoms, to remove malignant lesions before they spread, 
and to prevent the transition of benign precursor lesions to a malignancy [66]. The most common surgical procedures performed on cystic neoplasms of the pancreas are pancreaticoduodenectomies (70\%) and distal pancreatectomies (25\%). Other surgical procedures include total pancreatectomies, segmental resections such as middle segment pancreatectomy, and enucleation $(<5 \%)[25,28,90]$. Because IPMNs and MCNs display a diverse spectrum of biological and clinical behaviors, accurate diagnosis and preoperative assessment of these lesions are critical in determining the optimal management for these patients [91, 92]. For ideal clinical management, three different entities must be distinguished: main-duct (and mixed-type) IPMNs, branch-duct IPMNs, and MCNs.

\section{Main-Duct IPMNs}

Main-duct IPMNs and mixed variants have a high risk of becoming malignant and therefore are treated as premalignant lesions. Because it remains difficult to predict malignancy preoperatively even with thin-sliced cross-sectional imaging [76], resection should be recommended if the patient is an appropriate surgical candidate $[6,40,66,76,93]$. The surgical goal for main-duct and mixed-type IPMNs should be to eliminate all gross disease while attempting to achieve negative surgical margins (R0 resection). In most cases this can be achieved by partial pancreatectomy [40]. Although there is a belief that IPMNs are potentially multicentric because of a "field defect" involving the entire duct, leading some investigators to advocate total pancreatectomy [94, 95], presently we do not recommend this extreme approach. There are two main reasons why it is preferable to avoid total pancreatectomy whenever possible: first, it has been reported that, for malignant IPMNs, recurrence rates are similar whether total pancreatectomy or only partial pancreatectomy is performed [96, 97]; second, patients after total pancreatectomy must deal with the difficulties and dangers of complete endocrine and exocrine pancreatic insufficiency.

\section{Branch-Duct IPMNs}

Branch-duct IPMNs generally have a much lower risk (6\%-46\%) of harboring malignancy [40]. Moreover, small branch-duct IPMNs that are $<30 \mathrm{~mm}$ in diameter and do not contain mural nodules rarely have malignant histological features [77]. A recently published study of 145 patients with resected and pathologically confirmed branch-duct IPMNs reported that cancer was present in only $22 \%$ of the patients. There were no cancers when, in the absence of symptoms, the lesion was $<30 \mathrm{~mm}$ and was smooth-walled without mural nodules [19]. Thus, resectional therapy is reserved for symptomatic and/or large branch-duct IPMNs, or lesions with internal nodules shown by imaging. In accord with the Sendai consensus conference guidelines, small, asymptomatic, simple cysts can be observed with periodic surveillance, preferably by MRCP, at 6 - to 12 -month intervals, depending on their size [35, $40,77,98]$. Nearly $30 \%$ of branch-duct IPMNs may be multicystic and comprise two or more cysts, perhaps widely distributed throughout the gland. Surgical approaches to these multi-cystic pancreata have included segmental to total pancreatectomy; however, because the majority of these side-branch IPMNs have a low risk of harboring a malignancy, it seems prudent to design the resection to encompass only the areas of cystic neoplasm that meet the criteria for resection at that time and to leave the remainder to the surveillance program [19].

\section{MCNs}

MCNs, unless there are contraindications for surgery, should all be considered for resection [40]. The basis for this approach is that most MCN patients are relatively young at the time of diagnosis, and considering life expectancy and the ongoing risk for progression to malignancy, lifetime follow-up, with its attendant costs and anxieties, would be required. Furthermore, surgical resection (usually a left pancreatectomy) can be accomplished in 
experienced centers with minimal morbidity and no mortality [25, 99], and can be performed by laparoscopic means (at least for body and tail lesions) [100].

It is not always possible to ascertain with reliability the invasiveness of cystic lesions of the pancreas from preoperative imaging or even during intraoperative evaluation. Thus, whenever any doubt exists, a formal oncologic resection (pancreatoduodenectomy, left pancreatectomy, total pancreatectomy) with lymph node dissection should be undertaken $[40,89]$. Only in small lesions without any laboratory (e.g., elevated cancer antigen [CA] 19-9 [101]), clinical, or radiological suspicion of malignancy are lesser, local resections safe, but these should still be contingent upon a final intraoperative and histopathological assessment [40]. Limited pancreatic resection, which includes segmental resections, middle segment pancreatectomies, and enucleations, can be performed safely as long as negative ductal margins can be obtained [40, 102, 103].

During recent decades pancreatoduodenectomy and its modifications have become safe and effective, especially in experienced centers with a high patient volume [104]. In a recently published, combined series from the Massachusetts General Hospital and the University of Verona, which reported 145 branch-duct IPMN patients, the median postoperative length of stay after pancreatoduodenectomy was 9 days. The most common perioperative complication was a temporary pancreatic fistula, which occurred in $17 \%$ of cases. Only $4.8 \%$ of the patients required readmission for any postoperative complication [19]. Though there were no operative deaths and no surgical re-explorations observed in this series, pancreatectomy can result in serious complications and mortality [90]. Thus, given the association with mortality and outcome, resections for these frequently benign lesions should be performed in high-volume centers. Long-term results show that, after pancreatoduodenectomy, quality of life, as assessed by questionnaire, normally returns to the preoperative level within 6 months [105].

In summary, considering the currently expected good peri- and postoperative outcome following pancreatectomy, surgical resection for patients with main-duct IPMN, branch-duct IPMN $>30 \mathrm{~mm}$, or MCN, and any patient with related symptoms is recommended when the patient is an appropriate surgical candidate. The role of adjuvant chemotherapy and/or radiation is still undetermined, and further studies are required in this area [5, 6]. However, it is our institutional bias to treat invasive lesions arising in cystic lesions similar to pancreatic ductal adenocarcinoma.

\section{Conservative Management of IPMNs}

For asymptomatic branch-duct IPMNs, a conservative regimen is a yearly follow-up if the lesion is $<10 \mathrm{~mm}$ in size, a 6- to 12-month follow-up for lesions between $10 \mathrm{~mm}$ and 20 $\mathrm{mm}$, and 3- to 6-month follow-up for lesions $>20 \mathrm{~mm}$ [40, 106-109]. On follow-up studies, resection is recommended as soon as there is evidence of progress of the disease. Progress may be defined as sequential growth, new appearance of symptoms attributable to the cyst (e.g., pancreatitis), new presence of intramural nodules, cyst size $>30 \mathrm{~mm}$, or dilation $>6$ $\mathrm{mm}$ of the main pancreatic duct. If there is no change in several follow-up studies, the interval of follow-up may be lengthened after 2 years [40]. However, continued long-term surveillance is suggested.

\section{Diagnostic Follow-Up After Resection}

Because there are crucial differences among the types of mucinous cystic neoplasias of the pancreas, follow-up diagnosis must be adapted according to pathogenesis, multifocality, and prevalence of cancer. 
IPMNs are believed to progress slowly, showing a spectrum of neoplastic transformations before developing invasive cancer. Compared with their counterpart pancreatic ductal adenocarcinomas, they are characterized by a more favorable prognosis, even in malignant cases $[3,25,28,36,75,110,111]$. However, a subset of patients with IPMNs experience rapid recurrence or disseminated pancreatic adenocarcinoma after surgical resection and die of their disease within months [95, 112-115]. Patients with resected benign IPMNs (lowgrade and moderate dysplasia) and those with high-grade dysplasia do have a risk for recurrence in the remaining pancreas; if this occurs, they may benefit from further resection [40]. The frequency of this event and its relationship to surgical margins is not clear because, to date, most series have had relatively short median follow-up times. The recurrence rate seems to be about $7 \%$ in those patients with noninvasive IPMNs who undergo partial pancreatic resection with negative margins [3, 25, 95]. Furthermore, branchduct IPMNs have been reported to be multifocal in disparate regions of the pancreas in up to $30 \%$ of patients at the time of diagnosis $[116,117]$. This implies that there is a risk for developing progressive IPMNs in the remaining gland. Thus, there is need for follow-up, especially if there are unresected synchronous lesions [40]. In contrast, invasive IPMNs bear a high risk for recurrence $(48 \%-59 \%)[66,90]$ and should be evaluated every 6 months by imaging studies such as CT or MRI. Serum levels of CEA and CA 19-9 have no proven value in the follow-up of these patients [40].

Patients with resected benign MCNs do not need follow-up because these do not recur in the remaining pancreas after resection $[40,101]$. Several studies have convincingly shown that the risk for new MCNs following resection is zero [39, 40, 83, 84]. In contrast, patients with resected malignant MCNs should be followed every 6 months for local recurrence and distant metastasis (mainly hematogenous) using either CT or MRI [26, 40, 78].

\section{Conclusion}

Preoperative diagnosis and surgical management of cystic neoplasms of the pancreas remain interesting and challenging for the involved physician [90]. The optimal care of these patients is facilitated by an experienced team of physicians that includes a radiologist, gastroenterologist, surgeon, pathologist, and medical oncologist. Decisions about treatment options should be individualized and based on the patient's age, comorbidities, preferences, and willingness to undergo follow-up studies, as well as on the availability of safe pancreatic resection [40].

Because mucinous neoplasms have a wide range of histopathological features leading to pancreatic adenocarcinoma, they also provide a model offering a unique opportunity to study the slow-motion oncogenesis of epithelial carcinoma in the pancreas [26], an opportunity that does not yet exist for ductal adenocarcinoma itself. This natural human model may prove to be more valuable to our understanding of the pathobiology of pancreatic cancer than cell lines or animal models.

\section{Acknowledgments}

This work was supported by funding from the Karin Grunebaum Cancer Research Foundation and the German Research Foundation (S.F.).

\section{References}

1. Longnecker DS. Intraductal papillary-mucinous tumors of the pancreas. Arch Pathol Lab Med. 1995; 119:197-198. [PubMed: 7887770] 
2. Warshaw AL, Compton CC, Lewandrowski K, et al. Cystic tumors of the pancreas. New clinical, radiologic, and pathologic observations in 67 patients. Ann Surg. 1990; 212:432-443. discussion 444-445. [PubMed: 2171441]

3. Sohn TA, Yeo CJ, Cameron JL, et al. Intraductal papillary mucinous neoplasms of the pancreas: An updated experience. Ann Surg. 2004; 239:788-797. discussion 797-799. [PubMed: 15166958]

4. Fernández-del Castillo C, Targarona J, Thayer SP, et al. Incidental pancreatic cysts: Clinicopathologic characteristics and comparison with symptomatic patients. Arch Surg. 2003; 138:427-423. discussion 433-434. [PubMed: 12686529]

5. Sohn TA, Yeo CJ, Cameron JL, et al. Intraductal papillary mucinous neoplasms of the pancreas: An increasingly recognized clinicopathologic entity. Ann Surg. 2001; 234:313-321. discussion 321322. [PubMed: 11524584]

6. Conlon KC. Intraductal papillary mucinous tumors of the pancreas. J Clin Oncol. 2005; 23:45184523. [PubMed: 16002842]

7. Sarr MG, Murr M, Smyrk TC, et al. Primary cystic neoplasms of the pancreas. Neoplastic disorders of emerging importance-current state-of-the-art and unanswered questions. J Gastrointest Surg. 2003; 7:417-428. [PubMed: 12654569]

8. Ohhashi K, Murakami Y, Takekoshi T. Four cases of mucin producing cancer of the pancreas on specific findings of the papilla of Vater. Prog Dig Endosc. 1982; 20:348-351.

9. Kimura W, Nagai H, Kuroda A, et al. Analysis of small cystic lesions of the pancreas. Int J Pancreatol. 1995; 18:197-206. [PubMed: 8708390]

10. Balcom JH 4th, Rattner DW, Warshaw AL, et al. Ten-year experience with 733 pancreatic resections: Changing indications, older patients, and decreasing length of hospitalization. Arch Surg. 2001; 136:391-398. [PubMed: 11296108]

11. Payan MJ, Xerri L, Moncada K, et al. Villous adenoma of the main pancreatic duct: A potentially malignant tumor? Am J Gastroenterol. 1990; 85:459-463. [PubMed: 2183592]

12. Morohoshi T, Kanda M, Asanuma K, et al. Intraductal papillary neoplasms of the pancreas. A clinicopathologic study of six patients. Cancer. 1989; 64:1329-1335. [PubMed: 2548703]

13. Agostini S, Choux R, Payan MJ, et al. Mucinous pancreatic duct ectasia in the body of the pancreas. Radiology. 1989; 170:815-816. [PubMed: 2916036]

14. Tollefson MK, Libsch KD, Sarr MG, et al. Intraductal papillary mucinous neoplasm: Did it exist prior to 1980? Pancreas. 2003; 26:e55-58. [PubMed: 12657965]

15. Kloppel, G.; Solcia, E.; Longnecker, DS., et al. World Health Organization. International Histological Classification of Tumors. 2. Berlin: Springer; 1996. Histological typing of tumors of the exocrine pancreas; p. 15-21.

16. Longnecker, DS.; Adler, G.; Hruban, RH., et al. Intraductal papillary-mucinous neoplasms of the pancreas. In: Hamilton, SR.; Aaltonen, LA., editors. World Health Organization Classification of Tumors. Lyon, France: IARC Press; 2000. p. 237-241.

17. Hruban, RH.; Pitman, MB.; Klimstra, DS. Intraductal neoplasms. In: Hruban, RH.; Pitman, MB.; Klimstra, DS., editors. AFIP Atlas of Tumor Pathology, Series 4: Tumors of the Pancreas. Washington, DC: American Registry of Pathology; 2007. p. 75-110.

18. Furukawa T, Takahashi T, Kobari M, et al. The mucus-hypersecreting tumor of the pancreas. Development and extension visualized by three-dimensional computerized mapping. Cancer. 1992; 70:1505-1513. [PubMed: 1516002]

19. Rodriguez JR, Salvia R, Crippa S, et al. Branch-duct intraductal papillary mucinous neoplasms: Observations in 145 patients who underwent resection. Gastroenterology. 2007; 133:72-79. quiz 309-310. [PubMed: 17631133]

20. Tseng JF, Warshaw AL, Sahani DV, et al. Serous cystadenoma of the pancreas: Tumor growth rates and recommendations for treatment. Ann Surg. 2005; 242:413-419. discussion 419-421. [PubMed: 16135927]

21. Lewandrowski KB, Southern JF, Pins MR, et al. Cyst fluid analysis in the differential diagnosis of pancreatic cysts. A comparison of pseudocysts, serous cystadenomas, mucinous cystic neoplasms, and mucinous cystadenocarcinoma. Ann Surg. 1993; 217:41-47. [PubMed: 8424699]

22. Megibow AJ, Lombardo FP, Guarise A, et al. Cystic pancreatic masses: Cross-sectional imaging observations and serial follow-up. Abdom Imaging. 2001; 26:640-647. [PubMed: 11907731] 
23. Spinelli KS, Fromwiller TE, Daniel RA, et al. Cystic pancreatic neoplasms: Observe or operate. Ann Surg. 2004; 239:651-657. discussion 657-659. [PubMed: 15082969]

24. Gourgiotis S, Germanos S, Ridolfini MP. Presentation and management of pancreatic cystic neoplasms. J Clin Gastroenterol. 2007; 41:599-608. [PubMed: 17577117]

25. Salvia R, Fernández-del Castillo C, Bassi C, et al. Main-duct intraductal papillary mucinous neoplasms of the pancreas: Clinical predictors of malignancy and long-term survival following resection. Ann Surg. 2004; 239:678-685. discussion 685-687. [PubMed: 15082972]

26. Adsay NV, Conlon KC, Zee SY, et al. Intraductal papillary-mucinous neoplasms of the pancreas: An analysis of in situ and invasive carcinomas in 28 patients. Cancer. 2002; 94:62-77. [PubMed: $11815961]$

27. Kamisawa T, Fujiwara T, Tu Y, et al. Long-term follow-up of intraductal papillary adenoma of the pancreas. J Gastroenterol. 2002; 37:868-873. [PubMed: 12424574]

28. D'Angelica M, Brennan MF, Suriawinata AA, et al. Intraductal papillary mucinous neoplasms of the pancreas: An analysis of clinicopathologic features and outcome. Ann Surg. 2004; 239:400408. [PubMed: 15075659]

29. Sato N, Rosty C, Jansen M, et al. STK11/LKB1 Peutz-Jeghers gene inactivation in intraductal papillary-mucinous neoplasms of the pancreas. Am J Pathol. 2001; 159:2017-2022. [PubMed: 11733352]

30. Maire F, Hammel P, Terris B, et al. Intraductal papillary and mucinous pancreatic tumour: A new extracolonic tumour in familial adenomatous polyposis. Gut. 2002; 51:446-449. [PubMed: 12171972]

31. Chetty R, Salahshor S, Bapat B, et al. Intraductal papillary mucinous neoplasm of the pancreas in a patient with attenuated familial adenomatous polyposis. J Clin Pathol. 2005; 58:97-101. [PubMed: 15623495]

32. Abe T, Fukushima N, Brune K, et al. Genome-wide allelotypes of familial pancreatic adenocarcinomas and familial and sporadic intraductal papillary mucinous neoplasms. Clin Cancer Res. 2007; 13:6019-6025. [PubMed: 17947463]

33. Yamaguchi K, Yokohata K, Noshiro H, et al. Mucinous cystic neoplasm of the pancreas or intraductal papillary-mucinous tumour of the pancreas. Eur J Surg. 2000; 166:141-148. [PubMed: 10724492]

34. Eguchi $\mathrm{H}$, Ishikawa $\mathrm{O}$, Ohigashi $\mathrm{H}$, et al. Patients with pancreatic intraductal papillary mucinous neoplasms are at high risk of colorectal cancer development. Surgery. 2006; 139:749-754. [PubMed: 16782429]

35. Salvia R, Crippa S, Falconi M, et al. Branch-duct intraductal papillary mucinous neoplasms of the pancreas: To operate or not to operate? Gut. 2007; 56:1086-1090. [PubMed: 17127707]

36. Kitagawa Y, Unger TA, Taylor S, et al. Mucus is a predictor of better prognosis and survival in patients with intraductal papillary mucinous tumor of the pancreas. J Gastrointest Surg. 2003; 7:12-18. discussion 18-19. [PubMed: 12559180]

37. Thompson LD, Becker RC, Przygodzki RM, et al. Mucinous cystic neoplasm (mucinous cystadenocarcinoma of low-grade malignant potential) of the pancreas: A clinicopathologic study of 130 cases. Am J Surg Pathol. 1999; 23:1-16. [PubMed: 9888699]

38. Reddy RP, Smyrk TC, Zapiach M, et al. Pancreatic mucinous cystic neoplasm defined by ovarian stroma: Demographics, clinical features, and prevalence of cancer. Clin Gastroenterol Hepatol. 2004; 2:1026-1031. [PubMed: 15551256]

39. Zamboni G, Scarpa A, Bogina G, et al. Mucinous cystic tumors of the pancreas: Clinicopathological features, prognosis, and relationship to other mucinous cystic tumors. Am J Surg Pathol. 1999; 23:410-422. [PubMed: 10199470]

40. Tanaka M, Chari S, Adsay V, et al. International consensus guidelines for management of intraductal papillary mucinous neoplasms and mucinous cystic neoplasms of the pancreas. Pancreatology. 2006; 6:17-32. [PubMed: 16327281]

41. Sahani DV, Kadavigere R, Blake M, et al. Intraductal papillary mucinous neoplasm of pancreas: Multi-detector row CT with 2D curved reformations-correlation with MRCP. Radiology. 2006; 238:560-569. [PubMed: 16436817] 
42. Chiu SS, Lim JH, Lee WJ, et al. Intraductal papillary mucinous tumour of the pancreas: Differentiation of malignancy and benignancy by CT. Clin Radiol. 2006; 61:776-783. [PubMed: 16905386]

43. Irie $\mathrm{H}$, Honda $\mathrm{H}$, Aibe $\mathrm{H}$, et al. MR cholangiopancreatographic differentiation of benign and malignant intraductal mucin-producing tumors of the pancreas. AJR Am J Roentgenol. 2000; 174:1403-1408. [PubMed: 10789803]

44. Kalra MK, Maher MM, Sahani DV, et al. Current status of imaging in pancreatic diseases. J Comput Assist Tomogr. 2002; 26:661-675. [PubMed: 12439296]

45. Carbognin G, Zamboni G, Pinali L, et al. Branch duct IPMTs: Value of cross-sectional imaging in the assessment of biological behavior and follow-up. Abdom Imaging. 2006; 31:320-325. [PubMed: 16333711]

46. Sahani DV, Shah ZK, Catalano OA, et al. Radiology of pancreatic adenocarcinoma: Current status of imaging. J Gastroenterol Hepatol. 2008; 23:23-33. [PubMed: 18171340]

47. Waters JA, Schmidt CM, Pinchot JW, et al. CT vs MRCP: Optimal classification of IPMN type and extent. J Gastrointest Surg. 2008; 12:101-109. [PubMed: 17917784]

48. Koito K, Namieno T, Ichimura T, et al. Mucin-producing pancreatic tumors: Comparison of MR cholangiopancreatography with endoscopic retrograde cholangiopancreatography. Radiology. 1998; 208:231-237. [PubMed: 9646818]

49. Procacci C, Carbognin G, Accordini S, et al. CT features of malignant mucinous cystic tumors of the pancreas. Eur Radiol. 2001; 11:1626-1630. [PubMed: 11511881]

50. Yamaguchi K, Chijiwa K, Shimizu S, et al. Comparison of endoscopic retrograde and magnetic resonance cholangiopancreatography in the surgical diagnosis of pancreatic diseases. Am J Surg. 1998; 175:203-208. [PubMed: 9560120]

51. Adsay NV, Longnecker DS, Klimstra DS. Pancreatic tumors with cystic dilatation of the ducts: Intraductal papillary mucinous neoplasms and intraductal oncocytic papillary neoplasms. Semin Diagn Pathol. 2000; 17:16-30. [PubMed: 10721804]

52. Sugiyama M, Atomi Y. Intraductal papillary mucinous tumors of the pancreas: Imaging studies and treatment strategies. Ann Surg. 1998; 228:685-691. [PubMed: 9833807]

53. Kobayashi G, Fujita N, Lee S, et al. Correlation between ultrasonographic findings and pathological diagnosis of mucin producing tumor of the pancreas. Nippon Shokakibyo Gakkai Zasshi. 1990; 87:235-242. [PubMed: 2157912]

54. Kubo H, Chijiiwa Y, Akahoshi K, et al. Intraductal papillary-mucinous tumors of the pancreas: Differential diagnosis between benign and malignant tumors by endoscopic ultrasonography. Am J Gastroenterol. 2001; 96:1429-1434. [PubMed: 11374678]

55. Uehara H, Nakaizumi A, Tatsuta M, et al. Diagnosis of carcinoma in situ of the pancreas by peroral pancreatoscopy and pancreatoscopic cytology. Cancer. 1997; 79:454-461. [PubMed: 9028354]

56. Yamao K, Ohashi K, Nakamura T, et al. Efficacy of peroral pancreatoscopy in the diagnosis of pancreatic diseases. Gastrointest Endosc. 2003; 57:205-209. [PubMed: 12556785]

57. Hara T, Yamaguchi T, Ishihara T, et al. Diagnosis and patient management of intraductal papillarymucinous tumor of the pancreas by using peroral pancreatoscopy and intraductal ultrasonography. Gastroenterology. 2002; 122:34-43. [PubMed: 11781278]

58. Maker AV, Lee LS, Raut CP, et al. Cytology from pancreatic cysts has marginal utility in surgical decision-making. Ann Surg Oncol. 2008; 15:3187-3192. [PubMed: 18766406]

59. Michaels PJ, Brachtel EF, Bounds BC, et al. Intraductal papillary mucinous neoplasm of the pancreas: Cytologic features predict histologic grade. Cancer. 2006; 108:163-173. [PubMed: 16550572]

60. Sperti C, Bissoli S, Pasquali C, et al. 18-fluorodeoxyglucose positron emission tomography enhances computed tomography diagnosis of malignant intraductal papillary mucinous neoplasms of the pancreas. Ann Surg. 2007; 246:932-937. discussion 937-939. [PubMed: 18043094]

61. Baiocchi GL, Portolani N, Bertagna F, et al. Possible additional value of ${ }^{18}$ FDG-PET in managing pancreas intraductal papillary mucinous neoplasms: Preliminary results. J Exp Clin Cancer Res. 2008; 27:10. [PubMed: 18577196] 
62. Yamao K, Nakamura T, Suzuki T, et al. Endoscopic diagnosis and staging of mucinous cystic neoplasms and intraductal papillary-mucinous tumors. J Hepatobiliary Pancreat Surg. 2003; 10:142-146. [PubMed: 14505147]

63. Stelow EB, Stanley MW, Bardales RH, et al. Intraductal papillary-mucinous neoplasm of the pancreas. The findings and limitations of cytologic samples obtained by endoscopic ultrasoundguided fine-needle aspiration. Am J Clin Pathol. 2003; 120:398-404. [PubMed: 14502804]

64. Brugge WR, Lewandrowski K, Lee-Lewandrowski E, et al. Diagnosis of pancreatic cystic neoplasms: A report of the cooperative pancreatic cyst study. Gastroenterology. 2004; 126:13301336. [PubMed: 15131794]

65. Hruban RH, Takaori K, Klimstra DS, et al. An illustrated consensus on the classification of pancreatic intraepithelial neoplasia and intraductal papillary mucinous neoplasms. Am J Surg Pathol. 2004; 28:977-987. [PubMed: 15252303]

66. Wada K, Kozarek RA, Traverso LW. Outcomes following resection of invasive and noninvasive intraductal papillary mucinous neoplasms of the pancreas. Am J Surg. 2005; 189:632-636. discussion 637. [PubMed: 15862510]

67. Yamada M, Kozuka S, Yamao K, et al. Mucin-producing tumor of the pancreas. Cancer. 1991; 68:159-168. [PubMed: 2049738]

68. Adsay NV, Pierson C, Sarkar F, et al. Colloid (mucinous noncystic) carcinoma of the pancreas. Am J Surg Pathol. 2001; 25:26-42. [PubMed: 11145249]

69. Azar C, Van de Stadt J, Rickaert F, et al. Intraductal papillary mucinous tumours of the pancreas. Clinical and therapeutic issues in 32 patients. Gut. 1996; 39:457-464. [PubMed: 8949654]

70. Rivera JA, Fernández-del Castillo C, Pins M, et al. Pancreatic mucinous ductal ectasia and intraductal papillary neoplasms. A single malignant clinicopathologic entity. Ann Surg. 1997; 225:637-644. discussion 644-646. [PubMed: 9230804]

71. Sessa F, Solcia E, Capella C, et al. Intraductal papillary-mucinous tumours represent a distinct group of pancreatic neoplasms: An investigation of tumour cell differentiation and K-ras, p53 and c-erbB-2 abnormalities in 26 patients. Virchows Arch. 1994; 425:357-367. [PubMed: 7820300]

72. Z'Graggen K, Rivera JA, Compton CC, et al. Prevalence of activating K-ras mutations in the evolutionary stages of neoplasia in intraductal papillary mucinous tumors of the pancreas. Ann Surg. 1997; 226:491-498. discussion 498-500. [PubMed: 9351717]

73. Terris B, Ponsot P, Paye F, et al. Intraductal papillary mucinous tumors of the pancreas confined to secondary ducts show less aggressive pathologic features as compared with those involving the main pancreatic duct. Am J Surg Pathol. 2000; 24:1372-1377. [PubMed: 11023098]

74. Kobari M, Egawa S, Shibuya K, et al. Intraductal papillary mucinous tumors of the pancreas comprise 2 clinical subtypes: Differences in clinical characteristics and surgical management. Arch Surg. 1999; 134:1131-1136. [PubMed: 10522860]

75. Nakagohri T, Kenmochi T, Kainuma O, et al. Intraductal papillary mucinous tumors of the pancreas. Am J Surg. 1999; 178:344-347. [PubMed: 10587197]

76. Doi R, Fujimoto K, Wada M, et al. Surgical management of intraductal papillary mucinous tumor of the pancreas. Surgery. 2002; 132:80-85. [PubMed: 12110799]

77. Matsumoto T, Aramaki M, Yada K, et al. Optimal management of the branch duct type intraductal papillary mucinous neoplasms of the pancreas. J Clin Gastroenterol. 2003; 36:261-265. [PubMed: 12590239]

78. Sugiyama M, Izumisato Y, Abe N, et al. Predictive factors for malignancy in intraductal papillarymucinous tumours of the pancreas. Br J Surg. 2003; 90:1244-1249. [PubMed: 14515294]

79. Fernández-del Castillo C. Intraductal papillary mucinous neoplasms of the pancreas: A plea for prospective differentiation between main-duct and side-branch tumors. Ann Surg Oncol. 2005; 12:98-99. [PubMed: 15827786]

80. Volkan Adsay N. Cystic lesions of the pancreas. Mod Pathol. 2007; 20(suppl 1):S71-S93. [PubMed: 17486054]

81. Allen PJ, Jaques DP, D’Angelica M, et al. Cystic lesions of the pancreas: Selection criteria for operative and nonoperative management in 209 patients. J Gastrointest Surg. 2003; 7:970-977. [PubMed: 14675706] 
82. Izumo A, Yamaguchi K, Eguchi T, et al. Mucinous cystic tumor of the pancreas: Immunohistochemical assessment of "ovarian-type stroma. Oncol Rep. 2003; 10:515-525. [PubMed: 12684617]

83. Sarr MG, Carpenter HA, Prabhakar LP, et al. Clinical and pathologic correlation of 84 mucinous cystic neoplasms of the pancreas: Can one reliably differentiate benign from malignant (or premalignant) neoplasms? Ann Surg. 2000; 231:205-212. [PubMed: 10674612]

84. Wilentz RE, Albores-Saavedra J, Zahurak M, et al. Pathologic examination accurately predicts prognosis in mucinous cystic neoplasms of the pancreas. Am J Surg Pathol. 1999; 23:1320-1327. [PubMed: 10555000]

85. Cameron JL, Riall TS, Coleman J, et al. One thousand consecutive pancreaticoduodenectomies. Ann Surg. 2006; 244:10-15. [PubMed: 16794383]

86. Richter A, Niedergethmann M, Sturm JW, et al. Long-term results of partial pancreaticoduodenectomy for ductal adenocarcinoma of the pancreatic head: 25-year experience. World J Surg. 2003; 27:324-329. [PubMed: 12607060]

87. Wagner M, Redaelli C, Lietz M, et al. Curative resection is the single most important factor determining outcome in patients with pancreatic adenocarcinoma. Br J Surg. 2004; 91:586-594. [PubMed: 15122610]

88. Wilentz RE, Albores-Saavedra J, Hruban RH. Mucinous cystic neoplasms of the pancreas. Semin Diagn Pathol. 2000; 17:31-42. [PubMed: 10721805]

89. Falconi M, Salvia R, Bassi C, et al. Clinicopathological features and treatment of intraductal papillary mucinous tumour of the pancreas. Br J Surg. 2001; 88:376-381. [PubMed: 11260102]

90. Raut CP, Cleary KR, Staerkel GA, et al. Intraductal papillary mucinous neoplasms of the pancreas: Effect of invasion and pancreatic margin status on recurrence and survival. Ann Surg Oncol. 2006; 13:582-594. [PubMed: 16523362]

91. Schmidt CM, White PB, Waters JA, et al. Intraductal papillary mucinous neoplasms: Predictors of malignant and invasive pathology. Ann Surg. 2007; 246:644-651. discussion 651-654. [PubMed: 17893501]

92. Walsh RM, Vogt DP, Henderson JM, et al. Management of suspected pancreatic cystic neoplasms based on cyst size. Surgery. 2008; 144:677-684. discussion 684-685. [PubMed: 18847654]

93. Traverso LW. Surgical treatment of intraductal papillary mucinous neoplasms of the pancreas: The aggressive approach. J Gastrointest Surg. 2002; 6:662-663. [PubMed: 12399053]

94. Bendix Holme J, Jacobsen N, Rokkjaer M, et al. Total pancreatectomy in six patients with intraductal papillary mucinous tumour of the pancreas: The treatment of choice. HPB (Oxford). 2001; 3:257-262. [PubMed: 18333027]

95. Chari ST, Yadav D, Smyrk TC, et al. Study of recurrence after surgical resection of intraductal papillary mucinous neoplasm of the pancreas. Gastroenterology. 2002; 123:1500-1507. [PubMed: 12404225]

96. Jang JY, Kim SW, Ahn YJ, et al. Multicenter analysis of clinicopathologic features of intraductal papillary mucinous tumor of the pancreas: Is it possible to predict the malignancy before surgery? Ann Surg Oncol. 2005; 12:124-132. [PubMed: 15827792]

97. Maire F, Hammel P, Terris B, et al. Prognosis of malignant intraductal papillary mucinous tumours of the pancreas after surgical resection. Comparison with pancreatic ductal adenocarcinoma. Gut. 2002; 51:717-722. [PubMed: 12377813]

98. Fernández-del Castillo C. Surgical treatment of intraductal papillary mucinous neoplasms of the pancreas: The conservative approach. J Gastrointest Surg. 2002; 6:660-661. [PubMed: 12399052]

99. Lillemoe KD, Kaushal S, Cameron JL, et al. Distal pancreatectomy: Indications and outcomes in 235 patients. Ann Surg. 1999; 229:693-698. discussion 698-700. [PubMed: 10235528]

100. Matsumoto T, Hirano S, Yada K, et al. Safety and efficacy of laparoscopic distal pancreatectomy for the treatment of pancreatic disease. J Hepatobiliary Pancreat Surg. 2005; 12:65-70. [PubMed: 15754103]

101. Crippa S, Salvia R, Warshaw AL, et al. Mucinous cystic neoplasm of the pancreas is not an aggressive entity: Lessons from 163 resected patients. Ann Surg. 2008; 247:571-579. [PubMed: 18362619] 
102. Kiely JM, Nakeeb A, Komorowski RA, et al. Cystic pancreatic neoplasms: Enucleate or resect? J Gastrointest Surg. 2003; 7:890-897. [PubMed: 14592663]

103. Talamini MA, Moesinger R, Yeo CJ, et al. Cystadenomas of the pancreas: Is enucleation an adequate operation? Ann Surg. 1998; 227:896-903. [PubMed: 9637553]

104. Schafer M, Mullhaupt B, Clavien PA. Evidence-based pancreatic head resection for pancreatic cancer and chronic pancreatitis. Ann Surg. 2002; 236:137-148. [PubMed: 12170018]

105. Ohtsuka T, Tanaka M, Miyazaki K. Gastrointestinal function and quality of life after pyloruspreserving pancreatoduodenectomy. J Hepatobiliary Pancreat Surg. 2006; 13:218-224. [PubMed: 16708298]

106. Jang JY, Kim SW, Lee SE, et al. Treatment guidelines for branch duct type intraductal papillary mucinous neoplasms of the pancreas: When can we operate or observe? Ann Surg Oncol. 2008; 15:199-205. [PubMed: 17909912]

107. Pelaez-Luna M, Chari ST, Smyrk TC, et al. Do consensus indications for resection in branch duct intraductal papillary mucinous neoplasm predict malignancy? A study of 147 patients. Am J Gastroenterol. 2007; 102:1759-1764. [PubMed: 17686073]

108. Rautou PE, Levy P, Vullierme MP, et al. Morphologic changes in branch duct intraductal papillary mucinous neoplasms of the pancreas: A mid-term follow-up study. Clin Gastroenterol Hepatol. 2008; 6:807-814. [PubMed: 18304885]

109. Tanno S, Nakano Y, Nishikawa T, et al. Natural history of branch duct intraductal papillarymucinous neoplasms of the pancreas without mural nodules: Long-term follow-up results. Gut. 2008; 57:339-343. [PubMed: 17660227]

110. Adsay NV. The "new kid on the block": Intraductal papillary mucinous neoplasms of the pancreas: Current concepts and controversies. Surgery. 2003; 133:459-463. [PubMed: 12773972]

111. Traverso LW, Peralta EA, Ryan JA Jr, et al. Intraductal neoplasms of the pancreas. Am J Surg. 1998; 175:426-432. [PubMed: 9600293]

112. Cuillerier E, Cellier C, Palazzo L, et al. Outcome after surgical resection of intraductal papillary and mucinous tumors of the pancreas. Am J Gastroenterol. 2000; 95:441-445. [PubMed: 10685747]

113. Sho M, Nakajima Y, Kanehiro H, et al. Pattern of recurrence after resection for intraductal papillary mucinous tumors of the pancreas. World J Surg. 1998; 22:874-878. [PubMed: 9673562]

114. Loftus EV Jr, Olivares-Pakzad BA, Batts KP, et al. Intraductal papillary-mucinous tumors of the pancreas: Clinicopathologic features, outcome, and nomenclature. Members of the pancreas clinic, and pancreatic surgeons of mayo clinic. Gastroenterology. 1996; 110:1909-1918. [PubMed: 8964418]

115. Paal E, Thompson LD, Przygodzki RM, et al. A clinicopathologic and immunohistochemical study of 22 intraductal papillary mucinous neoplasms of the pancreas, with a review of the literature. Mod Pathol. 1999; 12:518-528. [PubMed: 10349991]

116. Kaneko T, Nakao A, Inoue S, et al. Intraoperative ultrasonography by high-resolution annular array transducer for intraductal papillary mucinous tumors of the pancreas. Surgery. 2001; 129:55-65. [PubMed: 11150034]

117. Kaneko T, Nakao A, Nomoto S, et al. Intraoperative pancreatoscopy with the ultrathin pancreatoscope for mucin-producing tumors of the pancreas. Arch Surg. 1998; 133:263-267. [PubMed: 9517737] 

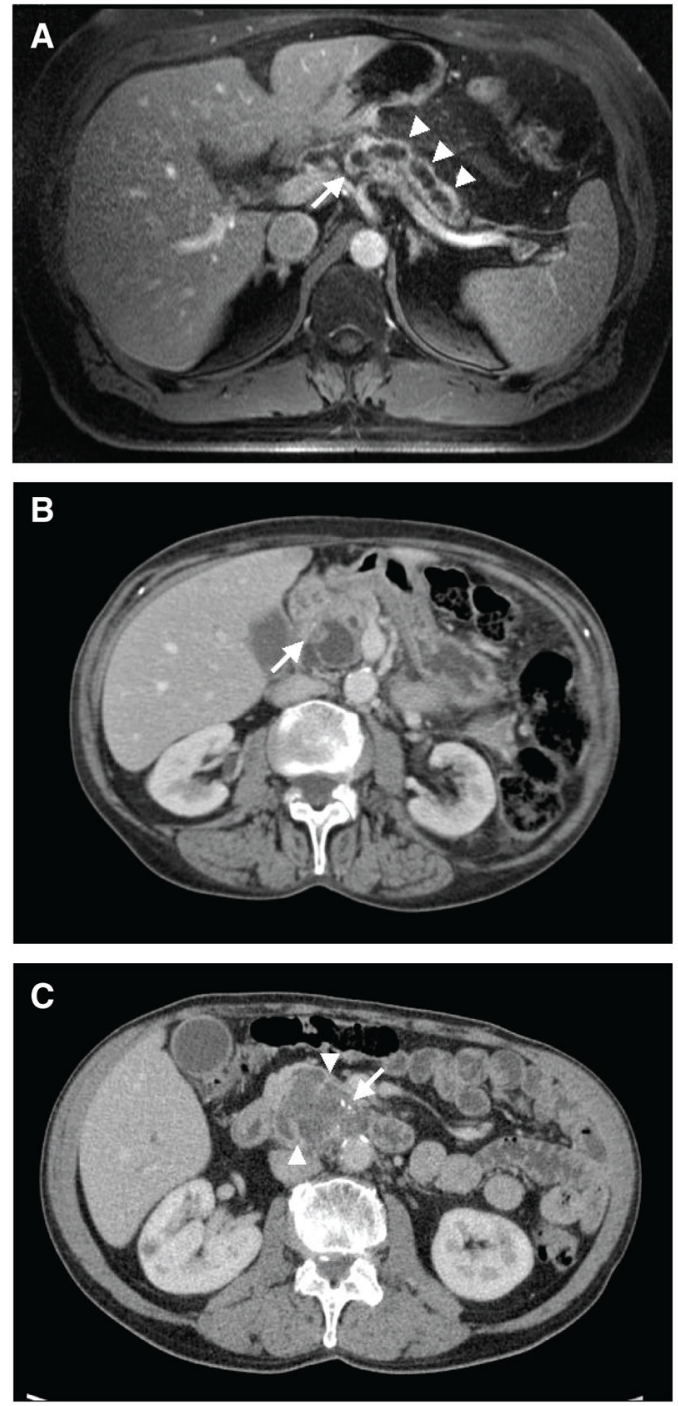

Figure 1.

Main-duct intraductal papillary mucinous neoplasm (IPMN). (A): Magnetic resonance imaging image (T1) of main-duct IPMN within the head of the pancreas (arrow) with associated dilation (arrowheads) of the pancreatic duct. (B): Computed tomography (CT) image of main-duct IPMN with suspicious enhancing nodule (arrow). (C): CT image of locally advanced invasive main-duct IPMN with septations (arrowheads) and calcifications (arrow). 

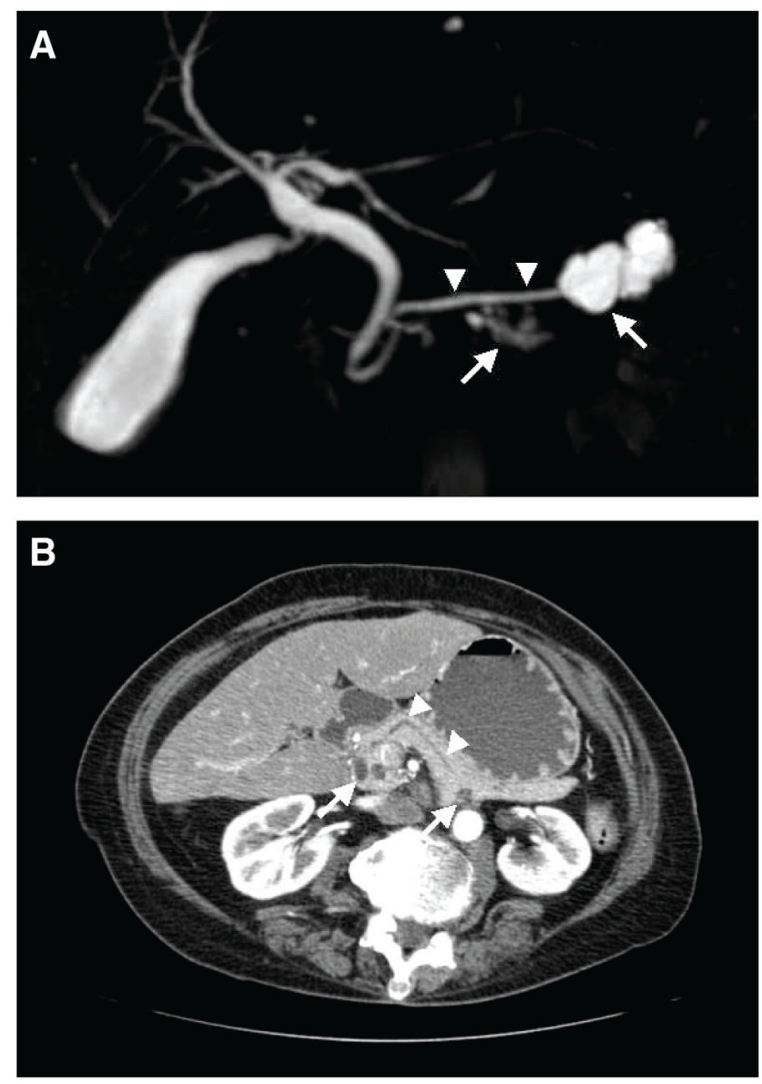

Figure 2.

Branch-duct intraductal papillary mucinous neoplasm (IPMN). (A): Magnetic resonance cholangiopancreatography image of multiloculated and multiseptated side-branch IPMN in the tail of the pancreas (arrows) without pancreatic ductal dilation (arrowheads). (B): Computed tomography image of multifocal branch-duct IPMN with numerous cystic lesions (arrows) with connection to the main pancreatic duct (arrowheads) within the head and body of the pancreas. 

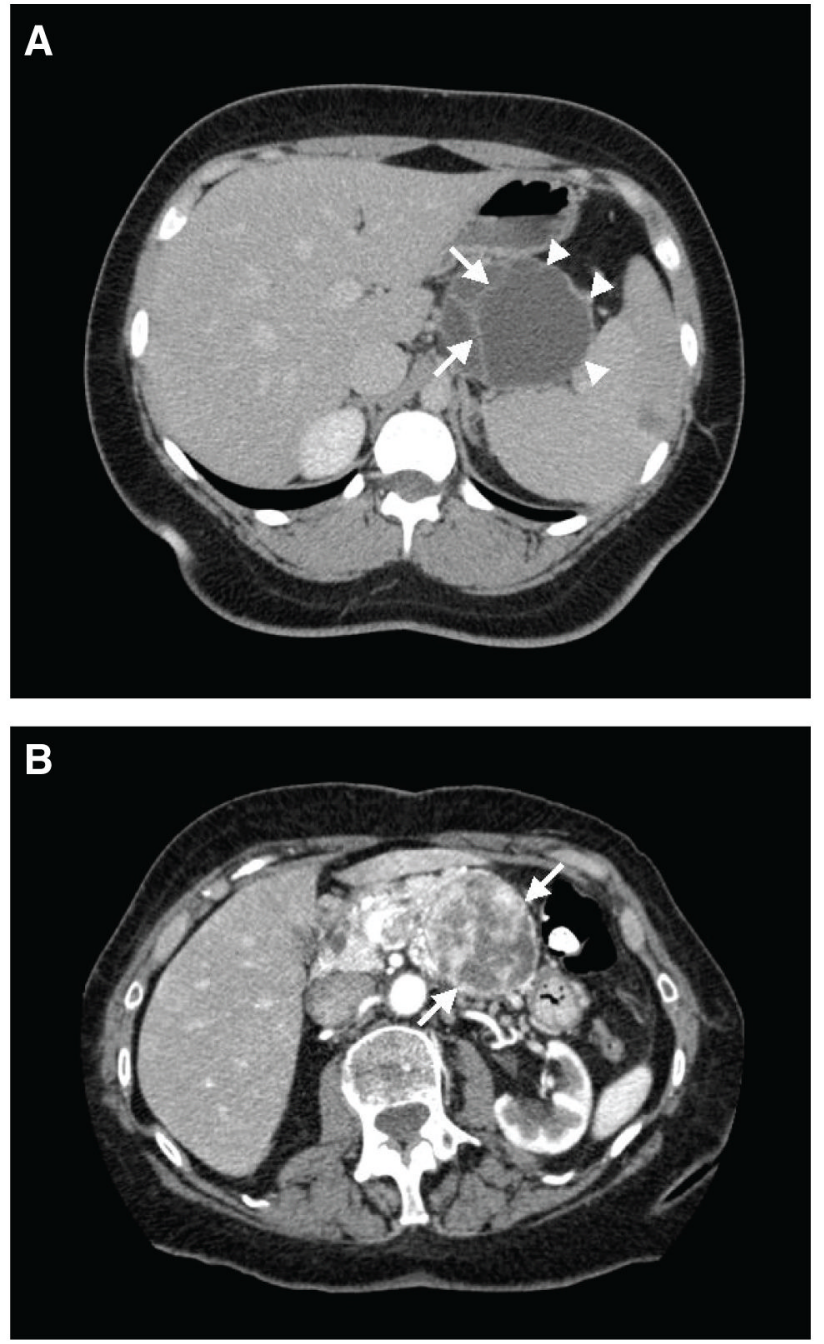

Figure 3 .

Mucinous cystic neoplasm (MCN). (A): Computed tomography (CT) image of large cystic lesion with numerous irregular internal septations (arrows) and a thin distinct wall (arrowheads). (B): CT image of invasive MCN within the body of the pancreas. The mass is markedly heterogeneous and lobulated (arrows). 

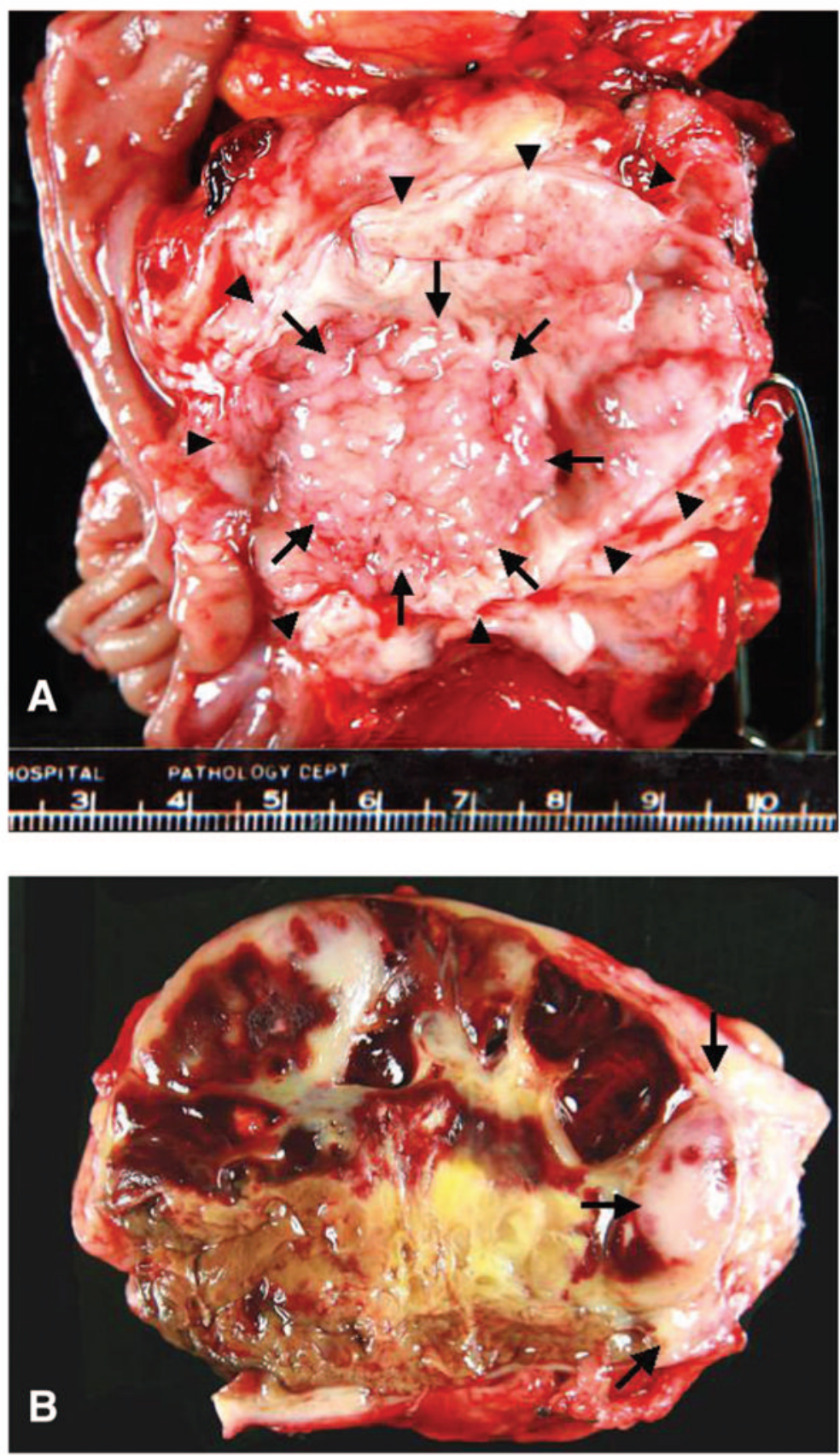

Figure 4.

Surgical specimens. (A): Main-duct intraductal papillary mucinous neoplasm: cystic lesion within the main duct in the head of the pancreas (arrowheads) containing a 3-cm area of carcinoma in situ (arrows). (B): Mucinous cystic neoplasm with invasive adenocarcinoma arising in the cystic wall (arrows). 

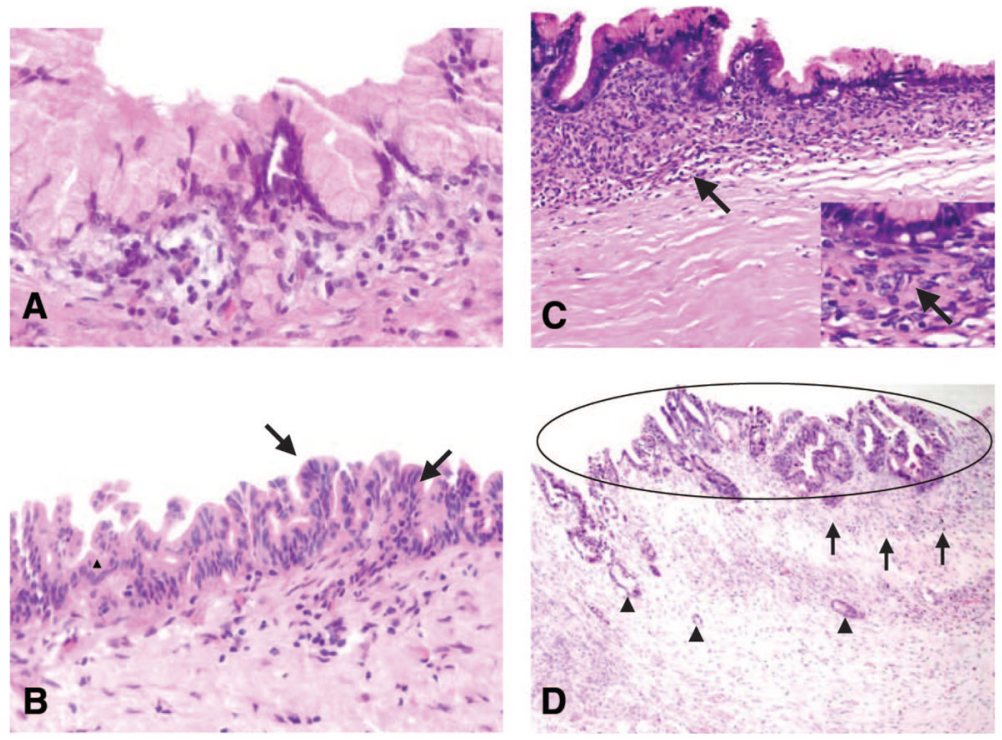

Figure 5.

Histological features, hematoxylin and eosin staining, 400x. (A): Low-grade intraductal papillary mucinous neoplasm (IPMN) (adenoma). The papillae show regular basally located nuclei with minimal cytologic atypia and abundant supranuclear mucin. (B): IPMN: highgrade dysplasia (carcinoma in situ). The papillae (arrows) show marked cytologic architectural disorganization and cellular atypia. (C): Mucinous cystic neoplasm (MCN), benign epithelium, and ovarian stroma. The epithelium of MCN can be hard to distinguish from that of IPMN. The distinctive feature of MCN is the hypercellular stroma, which shows all morphologic and immunophenotypic characteristics of ovarian stroma (arrow and inset). (D): MCN with malignant features. The circle identifies the region of high-grade dysplasia (in situ). The arrows identify ovarian stroma and the arrowheads identify the invasive ductal carcinoma. 
Table 1

Clinicopathological differences between intraductal papillary mucinous neoplasm (IPMN) and mucinous cystic neoplasm (MCN)

\begin{tabular}{|c|c|c|}
\hline Feature & IPMN & MCN \\
\hline Female to male ratio & $1: 1$ & $20: 1$ \\
\hline Mean age at presentation & $66 \mathrm{yrs}$ & $45 \mathrm{yrs}$ \\
\hline Predominant location of the tumor & Head $(61 \%-67 \%)$ & Body/tail $(93 \%)$ \\
\hline Involvement of pancreatic ducts & Present & Rare \\
\hline Malignant features (carcinoma in situ or invasive cancer) & Main-duct, $70 \%$; branch-duct, $25 \%$ & $6 \%-36 \%$ \\
\hline $\begin{array}{l}\text { 5-year disease-specific survival rate for benign, borderline, and noninvasive } \\
\text { malignant neoplasms }\end{array}$ & $100 \%$ & $100 \%$ \\
\hline 5-year survival rate for invasive cancer & $60 \%-70 \%$ & $50 \%-60 \%$ \\
\hline Recurrence after R0 resection & Benign, $7 \%-10 \%$; malignant, $25 \%-30 \%$ & $0 \%$ \\
\hline
\end{tabular}

